The Committee has continued to give thought to ways and means of ensuring the maximum economy in the expenditure of capital funds, and standards of accommodation of various types, based on analyses of comparable buildings, on which universities can base their applications to the Committee for grants for new accommodation, have been suggested. The Committee has also considered and adopted new methods, based on cost analyses, of assessing grants for halls of residence and for science buildings; the new system of assessing grants for science buildings distinguishes between the cost of the building with its basic requirements in the way of heating, lighting and ventilation and its special requirements in the way of services, which may vary greatly.

The number of full-time students in British universities increased further to 100,204 , compared with 95,442 in 1958-59, and statistics collected in October 1959 showed a university population of about 102,000. There were 6,084 full-time and 2,270 part-time students from overseas within the British Commonwealth, and 4,116 full-time and 1,944 part-time students from foreign countries; for 1957-58 the figures were 6,180 and 2,208 for the Commonwealth, and 3,982 and 1,904 for foreign countries. Of fulltime men students, $36 \cdot 8$ per cent were in arts, $24 \cdot 2$ per cent in pure science, 19.5 per cent in technology, and 12.5 per cent in medicine; these figures compare with $36 \cdot 4,23 \cdot 7,19 \cdot 0$ and $13 \cdot 7$ respectively, in 1957 58. For full-time women students, the corresponding figures for 1958-59 are $62 \cdot 6,20 \cdot 7,1 \cdot 0$ and $11 \cdot 9$, respectively, and for $1957-58,63.5,20 \cdot 0,0.8$ and $12 \cdot 1$, respectively. Full-time advanced students of pure science numbered 4,071 (34.9 per cent); of technology, 2,125 (18.2 per cent); and of medicine, $900(7.7$ per cent) ; 3,185 students were taking postgraduate teacher-training courses.

Of the full-time students, 80,805 were reading for a first degree, 3,928 for a first diploma, and 14,839 were engaged in research or other advanced work; the corresponding figures for 1957-58 were 76,687, 3,937 and 14,069 , respectively. Of the new full-time students, $24 \cdot 1$ per cent were in pure science, $16 \cdot 2$ per cent in technology and 8.9 per cent in medicine; in 1957-58 the corresponding figures were $24 \cdot 0,15 \cdot 4$ and $9 \cdot 1$ per cent, respectively.

The proportion of assisted students was 80.5 per cent compared with $79 \cdot 2$ per cent in 1957-58 and 71.9 per cent in $1953-54$, ranging from 92.4 per cent in Wales, 87.5 per cent in English universities, excluding Oxford, Cambridge and London, to $70 \cdot 6$ per cent for Scotland. Full-time teaching and research staff increased to 10,823 , compared with 10,542 in 1957-58. The proportion of full-time students residing in colleges or halls of residence was $26 \cdot 6$ per cent, compared with $26 \cdot 4$ per cent in $1957-58 ; 49.6$ per cent were in lodgings and 23.8 per cent at home, but these proportions vary widely between men and women and between institutions.

Of the recurrent income of $£ 52,273,306$ (an increase of $£ 2,855,004$ in $1957-58$ ), $£ 36,448,118$ was from Parliamentary grants $(69.7$ per cent), $£ 5,739,316$ (11.0 per cent) from fees, $£ 1,795,344$ from endowments, $£ 1,500,918$ from local authority grants, $£ 479,093$ from donations and subscriptions, and $£ 3,657,530(7 \cdot 0$ per cent) from payments for research. Non-recurrent grants in respect of capital expenditure amounted to $£ 16,554,483$, compared with $£ 11,816,479$ in 1957-58; and of the recurrent expenditure of $£ 51,526,275$-an increase of $£ 3,191,222$ on $1957-58$ $6 \cdot 8$ per cent was spent on administration, 44.5 per cent on salaries and superannuation of teaching staff, $11 \cdot 0$ per cent on departmental wages, $13 \cdot 2$ per cent on departmental and laboratory maintenance, 3.4 per cent on repairs and maintenance of buildings, and $\mathbf{9} \cdot \mathbf{7}$ per cent on rates, insurance, heating, lighting, etc. Expenditure on libraries, at $£ 1,979,945$, remained at 3.8 per cent of the total.

\title{
WIND TUNNELS AND FLOW VISUALIZATION
}

\begin{abstract}
$\mathrm{T}$ HE Fluid Dynamics Panel of AGARD held technical sessions at Istanbul, Turkey, during October 3-4. Fifteen papers were presented, the two main topics being the 'industrial' use of wind tunnels, and flow visualization. 'The term 'industrial' used in this context means 'non-aeronautical' ; and these topics were chosen for this particular meeting because of the special requirements of the host nation, which has little aeronautical industry. The meeting also presented a rare opportunity for workers in a field of aerodynamics which, while it does not usually receive the consideration of bodies concerned with aeronauties, is not afforded much prominence in the proceedings of the various engineering institutions to which the work is relevant.

The titles of the ten papers presented on industrial aerodynamics showed a similarity which was reflected to a large extent in the contents of the papers. Nevertheless the papers revealed a very wide diversity of problems, ranging from work on insect flight (using live subjects) to that of the aerodynamic oscillations of long suspension bridges. The introductory paper
\end{abstract}

by Mr. C. Scruton (United Kingdom) gave a brief review of the work carried out at the National Physical Laboratory. This was classified under three main categories: (1) the study of flow problems; (2) the assessment of the steady-wind forces and pressures on vehicles, ships, buildings, etc.; (3) the oscillatory effects of wind on structures. The techniques used and the conditions for similarity of behaviour between the model and the full scale were briefly indicated. In the first category most of the work was concerned with the flow over the decks of ships, and with pollution from the effluent of industrial chimneys, either with regard to the adjacent buildings or to the surrounding countryside. The oscillatory effects of wind were dealt with at somewhat greater length, with particular mention of the oscillations which can be induced by an air-stream on suspension bridges or tall stacks, and in tube arrays, such as are found in heat exchangers. It is now usual to carry out aerodynamic stability tests in connexion with all major suspension bridge projects, and, for this purpose, it has been shown that costly 
and time-consuming tests of aeroelastic models of the complete bridge are unnecessary and that the simple and cheaper 'sectional' model technique, in which a model of a representative length of the suspended structure is mounted on springs in the wind tunnel, is adequate. These tests have been usually carried out in a steady windstream, but on occasions it has been necessary to investigate the possibility of buffeting oscillations of the bridge arising from its immersion in the eddying wake of a nearby bridge. The windexcited oscillations of tall circular stacks are usually in bending modes transverse to the wind direction, and are due to the alternating 'lift' forces produced by the shedding of vortices from alternate sides of the section. Whether or not a stack oscillates depends on the natural frequency (on which depends the critical speed for instability) and on the structural damping. Artificial structural damping has been used to suppress the oscillations, but it may be that a more satisfactory solution is to be found in modifications to the cross-sectional shape which destroy the asrodynamic excitation. One such device which has proved successful was developed at the National Physical Laboratory, and consists of a three-start strake wound helically round the surface of the stack. This has the effect of destroying the regular periodicity in the formation of vortices. The top of a stack may be forced also into oscillations as an elastic ring by the action of the vortices. A ciné-film was shown which records such an occurrence at a power station in England and provided a graphic illustration of this effect.

The paper by Mr. P. J. Pocock (Canæda) provided a most complete review of the industrial uses to which wind tunnels have been put in various countries, together with a comprehensive bibliography of no less than 385 references. The range of subjects investigated is very wide : meteorology, water conservation, soil erosion by wind, the mechanics of wind-driven snow, dust transport, are included as well as those discussed by Scruton. The aerodynamics of sails is now receiving attention at the University of Southampton. Pocock also referred to the work on animal flight which has been carried out in wind tunnels. This ranges from the testing of dead or sculptured birds to the more intriguing measurements on live insects which were tethered on a delicate and intricate. wind-tunnel balance and their performance in flight measured as they flew against the horizontal wind.

In his paper on the aerodynamic problems of motor-cars Prof. H. Schlichting (Germany) demonstrated the very considerable saving in fuel consumption which has been achieved on the Volkswagen lorry by a modification to the frontal shape suggested by wind-tunnel tests. Reference was also made to the use of such tests to obtain data required for assessing the directional stability at high speeds of the Volkswagen private car, and of the stream-lined NSU motor bicycle which attained the world's speed record.

Prof. G. H. Strom (United States) discussed several interesting aspects which had been studied at New York University. With the reduced linear scale necessary, the representation in a wind tunnel of portions of the atmosphere, to include motions of mechanical and thermal origin, was a complex problem. The determination of the appropriate scale criteria needed further development, particularly when convective air currents were significant. Prof. Strom mentioned experiments in which powdered borax had been used to simulate snow in tests of snow drifting, and tests to study the production of capillary waves on a water surface.

A brief paper by Mr. H. Petersen (Denmark) described a wind tunnel especially suited for work in industrial aerodynamics. The tunnel design was based on the model-law proposed by Dr. Martin Jensen to provide the correct simulation for phenomena in which the influence of the vertical gradient of wind speed near the ground is significant.

The range of the problems investigated in wind tunnels was extended still further by the subsequent speakers. At Lille, A. Martinot-Lagarde (France) has studied mine ventilation, the fluid-flow in heat exchanges, and, more remarkably perhaps, the drag of fishing nets. A surprising result of the last-mentioned tests was that the drag of a net of nylon material was only 0.7 that of a net of similar configuration in cotton.

An open-jet type wind tunnel at the National Luchtvaarlaboratorium has been used extensively by Mr. N. Feiss (Netherlands) for investigating a wide variety of industrial problems. Some interesting techniques have been developed for predicting the nuisance caused by the deposition of rain and snow on the windscreens of vehicles.

Profs. R. Clay Porter and F. K. Boutwell (United States) have used the low-speed wind tunnel at the University of Michigan for some detailed work on air pollution from industrial effluents. An investigation at present in progress concerns natural draught cooling towers. It is elaimed that such work has resulted in considerable financial savings by the industry.

The subject-matter of the two remaining papers, by Mr. R. F. Creasey and Mr. K. Emslie (United Kingdom), "Industrial Uses of Wind-tunnels with Particular Reference to Wind Machines", and by Mr. L. E. Leavey (United Kingdom), "Wind-tunnel Tests to determine the Efficiency of a Proposed Extension to a Welding Shed on Suppressing Draughts", may be gathered from their titles. It may be noted that these were the only papers to describe work of a non-aeronautical character carried out in the wind tunnels of aircraft manufacturing firms. Such investigations have been mostly carried out either by the universities or by national scientific establishments. The subjects treated and the techniques described in the papers from the several countries were broadly similar. However, there were sufficient differences to avoid repetition, and to make all the papers very valuable and worth-while contributions to an art which is rapidly increasing in its importance and in its application to engineering design.

The first of three papers on flow-visualization was presented by H. Werle (France), and described a number of facilities, using water as the fluid medium, which allow qualitative work to be carried out on problems of air-flow. These facilities included a narrow tank for viscous-flow work, a water tunnel for incompressible flows, and a free-surface tank for the supersonic analogy. The paper was given with the aid of an excellent cine film in colour, the use of dye streamers of different colours enabling threedimensional flows to be followed very easily. Among the phenomena shown in this film were the flow of swept wings in which the leading-edge vortices 'burst' at a little distance downstream, the effect of 'blowing' over flaps and ablation effects on a bluff body. For the latter experiment the body was moulded in ice, 
but no similitude with the full-scale phenomenon was claimed.

Mr. R. L. Maltby (United Kingdom) based his presentation on one of five papers which have been prepared for an AGARDOgraph on flow-visualization, and which describes the methods used in British low-speed wind tunnels. In addition to the usual 'smokes', mention was made of the use of soap bubbles. Condensation trails can form a natural method of visualizing the leading-edge vortices from swept wings when the vorticity is of sufficient strength to produce the condensation.
Moving from methods suitable for use in low-speed tunnels to those for high-speed flow visualization, J. L. Solignac (France) described interferometric apparatus used at the Office National d'Etudes et de Recherches Aéronautiques. One of these employed split-beam interferometry, whereas the other, which was developed there, was a schlieren-interferometer system using polarized light. As compared with the ordinary schlieren system, the latter method was claimed to have the advantages of simplicity as well as of the ability to make quantitative measurements.

C. Scruton

\section{PRIMARY AND INITIAL EFFECTS OF IONIZING RADIATIONS}

\begin{abstract}
DROF. G. M. FRANK organized in Moscow during October 18-22, on behalf of the Academy of Sciences of the U.S.S.R., an international symposium which was sponsored by Unesco and the International Atomic Energy Agency. Half the thirty participants came from countries other than the U.S.S.R. As the contributions ranged widely and encompassed several disciplines, the classification under the headings chosen for this report must be somewhat arbitrary.
\end{abstract}

\section{Interference with Intracellular Structures}

The concept that the initial radiochemical reaction leading to the death of a cell is brought about by interference with the intracellular organization of the cell found support from many of the participants. In the first of the scientific papers, P. Alexander (London) reviewed the chemical data concerning damage to proteins and nucleic acids by ionizing radiation, and concluded that reactions of this kind, although they occur in cells, as do many others, did not meet the requirements for the radiochemical events that initiate cell death. He suggested the phospholipids of the intracellular membranes as a more probable site. Since one of the most frequent and earliest biochemical lesions following irradiation is an increase in enzymatic activity, it had been proposed by Bacq and Alexander (enzyme-release hypothesis) that radiation interferes with the structures within the cell that are responsible for its essential compartmentalization. G. M. Frank (Moscow) provided a striking demonstration of an increase in metabolism within an hour of irradiation by showing that the time taken for oxygen-levels in the brain to return to normal after a short period of inhalation of pure oxygen was less in an irradiated animal. The same technique also revealed that radiation immediately interferes with the homeostatic maintenance of oxygen-levels in tissues.

L. A. Stocken (Oxford) and M. Errera (Brussels) described their experiments on the immediate effect of X-rays on the metabolism of the nuclei of rat thymocytes. Stocken concluded that low doses produce local disorganization of the nucleus, which alters binding sites, and he outlined his current research programme directed to discovering the factors that maintain the nucleus in an organized state. Changes in the structure and behaviour of cytoplasmic fine structures within minutes of irradiation were seen by M. N. Meissel (Moscow) using fluorescent vital staining and by A. Shabadash
(Moscow) with histochemical techniques. O. Hug (Munich) reported that smooth muscle was unexpectedly radiosensitive, and contracted with a dose of a few hundred röntgens so long as this was given at a sufficiently high dose-rate. He interpreted this effect as a tomporary change in permeability of the nerve (or muscle) membrane.

A. M. Kuzin (Moscow) observed mitotic inhibition in the tip of the bean root (Vicia faba) although only a leaf had been irradiated. An antimitotic substance could be extracted from irradiated leaves and on purification was shown to be a soluble oxidation product of a polyphenol (a quinonoid substance). Evidence was found in support of the view that the active substances were formed as the result of the release (activation?) of enzyme peroxidases from cytoplasmic organelles.

A. J. Passynsky (Moscow) was led by general kinetic considerations to the view that death of a cell by radiation was due to interference with the orderly sequence of biochemical events due to damage to the interphases at which they occur. Experiments in a model system illustrated the breakdown of membranes by $20,000 \mathrm{r}$. of X-rays. Particles of an enzyme were coated with a layer, approximately $100 \AA$. thick, of ribonucleic acid and then suspended in a solution of substrate. Enzymatic activity was accelerated on irradiation because the permeability of the ribonucleic acid film was increased. N. N. Doemin (Moscow) carried out a very detailed study of the effect of radiation on the lipids and lipoproteins in different sub-cellular fractions (microsomes, mitochondria); surprising differences were observed in different organs of the rats, though in every case early lesions among lipids were observed.

B. N. Tarusoff (Moscow) has found that the concentration of lipid peroxides in tissues of mice increases with time after irradiation, which initiates the oxidation chain. A correlation was seen between the peroxide-level and the time of death of the animal, and Tarusoff supports the view advanced some years ago by J. St. L. Philpot that toxic peroxides contribute to radiation death in mammals.

Genetic techniques using 'sexual' transfer between biochemically deficient mutants were used by $H$. Marcovich (Paris) to show that the killing of $\boldsymbol{E}$. coli (that is, the loss of ability of the cells to proliferate indefinitely and form colonies) could not be attributed to a dominant lethal mutation. K. Tobias (Berkeley), on the other hand, argued that killing of yeast and the very complex relationship between ploidy and radiosensitivity could be adequately explained as the 